\title{
A Snapshot of Early Adopters of E-journals: Challenges to the Library
}

\author{
Martin J. Brennan, Julie M. Hurd, Deborah D. Blecic, \\ and Ann C. Weller
}

Studies documenting the usage patterns of electronic journals have compared print and e-journal characteristics, surveyed faculty for their perceptions and expectations, and analyzed the impact on library practices. This study, a qualitative exploration of a wide array of issues related to the research and teaching habits of early adopters of e-journals in a research setting, was conducted in the spring of 2001 with faculty in the basic and health sciences at the University of Illinois at Chicago. Open-ended questionnaires provided a framework to wide-ranging discussions of perceptions, expectations, and changing practices pertaining to e-journals and other electronic resources. The results were analyzed with a specific focus on shared behaviors and values, discipline-dependent variations, and changing research and teaching habits. Several challenges for library resources and services are identified and discussed.

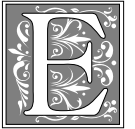

lectronic publishing has transformed the collections and services provided by research libraries. In the basic sciences and the health sciences, online databases have replaced print indexes and abstracts; more recently, e-journals have become an alternate format for those reading the research literature. The library literature now includes numerous quantitative studies that document the print-to-electronic migration. However, usage numbers tell only part of the story; a qualitative analysis of the impact of e-journals and other electronic resources can provide another perspective. This report describes an interview-based study of academic scientific and health science researchers that explored faculty members' usage of, and attitudes toward, electronic resources, particularly as related to their research and teaching activities.

\section{Literature Review}

Carol Tenopir and Donald W. King published a monograph in 2000 that, at present, is likely the most detailed and comprehensive analysis of emerging developments in scientific journal publishing. ${ }^{1}$ The authors synthesized findings

Martin J. Brennan is Assistant Information Services Librarian in the Library of the Health Sciences at the University of Illinois at Chicago; e-mail: brennan@uic.edu. Julie M. Hurd is Science Librarian and Coordinator of Digital Library Planning in the Science Library at the University of Illinois at Chicago; e-mail: jhurd@uic.edu. Deborah D. Blecic is Bibliographer for Life and Health Sciences in the Library of the Health Sciences at the University of Illinois at Chicago; e-mail: dblecic@uic.edu. Ann C. Weller is Curator of Special Collections in the Library of the Health Sciences at the University of Illinois at Chicago; email:acw@uic.edu. 
from more than a hundred studies of scientific communication, including scientists (as authors and readers), publishers, and organizations (universities, research institutes, and libraries). In addition, they drew on data from published surveys of more than 13,500 scientists and thirty-two organizations and tracked usability characteristics of a sample of 715 scientific scholarly journals from 1960 to 1995 . Tenopir and King's research was directed toward furthering a better understanding of key issues and questions among journal system participants.

Studies that use the perspective of the journal reader have identified various aspects of content and functionality as features that seem likely to influence whether users will adopt e-journals. Carol Franck and Holly Chambers focused on timeliness and content in their comparative study of twenty-six journals, primarily in social sciences and humanities, that were received in both print and electronic versions by the SUNY Potsdam library. Issue-by-issue comparisons provided quantitative data on the availability of content by type as well as quantity and quality of graphics and other nontextual features of articles. The authors found substantial differences across publishers with respect to equivalency of print versus electronic issues, availability of issues, and quality of graphics. ${ }^{2}$ Shelley Shaffer and colleagues at the Scripps Institution of Oceanography Library compared the timeliness of print versus electronic issues of journals to which the library subscribed in both formats. The authors collected and analyzed data on receipts over a six-week period to support collection development decisions, and reported that " $84 \%$ of our print issues had electronic versions at the time of receipt, either the same issue number or future issue numbers." 3 Speaking at the 1998 Charleston Conference, Anthony Watkinson focused on issues of ejournal functionality, emphasizing the reader role. He affirmed the importance of browsing and discovery to scientists as well as convenient desktop access to journal content. Moreover, he offered ex- amples: PDF as a preferred format that provided both text and graphics, and linking that supported easy and seamless navigation across related information. Watkinson urged a continuing conversation among scientists, librarians, and publishers to ensure that new products reflect what users want. ${ }^{4}$

\section{All of these studies describe faculty increasingly comfortable with e- journals and less attached to their print counterparts.}

Sarah Pederson and Rosemary Stockdale surveyed scientists at seven universities in Great Britain, and followed up with in-depth interviews of some, to assess their attitudes toward and use of ejournals. Their respondents identified a critical mass of content as well as functionalities that supported ease of searching and navigating as critical determinants in their adoption of an electronic resource. ${ }^{5}$ Christie T. Degener reported on her experiences with faculty using e-journals in a medical library setting. Health sciences researchers with whom she spoke valued the convenience and time-saving features of e-journals, including ease of searching and navigating among articles and twenty-four-hour access from office, laboratory, and home. The researchers cited the ability to print articles of interest, complete with color illustrations and figures, on printers located in their own departments. Degener also found some evidence of changing approaches to reading journals. For example, one scientist who once scanned tables of contents now uses targeted keyword searches to identify newly published articles of interest. Degener speculated on whether changes in reading habits would ultimately affect citation patterns. ${ }^{6}$

Other related research relied on statistical analyses of system-generated data from providers or vendors of electronic resources. Alan Dawson analyzed e-journal access data and attempted to relate them to the activities of browsing, reading, and searching by users of a collection 
of 249 e-journals provided by a British consortial journal service known as BUBL. Dawson offered an approach that infers details of use patterns from statistics; he proposed a measure of use, a SearchBrowse Ratio, that he argued is more meaningful than a simple count of accesses to a resource. ${ }^{7}$ Linda S. Mercer addressed the complexity and challenges in measuring use of digital resources. She focused on journal usage statistics, whether provided by vendors or generated institutionally from transaction logs, describing how use statistics for Highwire Press and Ovid journals provide not only a sense of the volume of use, but also the breadth across disciplines and user groups. Moreover, she recommended that librarians explore measurement issues both locally and at higher levels to establish a set of minimal standards for basic use statistics. ${ }^{8}$ Deborah D. Blecic, Joan B. Fiscella, and Stephen Wiberley analyzed available vendor-generated statistics with an eye toward consistency with International Coalition of Library Consortia guidelines and suggested ways vendors could modify reporting practices to provide more useful statistics for libraries. ${ }^{9}$ David H. Morse and William A. Clintworth compared data from full-text offerings from Ovid Biomedical Journals with their print counterpart's reshelving patterns and found online usage typically ten times that of the print counterpart. ${ }^{10}$ Sandra L. DeGroote and Josephine Dorsch found that although increases were measured in online versions of existing print journal usage over time, print usage declined across the board, whether or not the library retained an electronic subscription. ${ }^{11}$

Further studies of faculty users of ejournals surveyed perceptions and adoption patterns, opening other avenues for statistical analysis. Suely Gomes and Jack Meadows reported the findings of a 1996 survey of science faculty and staff at British universities, with a focus on perceptions, acceptability, and usability of e-journals. ${ }^{12}$ Susan E. Hahn, Cheri Speier, Jonathan Palmer, and Daniel Wren reported on findings of a 1998 survey of three hundred business school faculty whose libraries were members of the Association of Research Libraries (ARL), noting a slightly slower adoption rate than the scientific community with a different set of values and perceptions. ${ }^{13}$ Deborah Lenares described findings from a 1999 survey of five hundred faculty members at twenty universities with ARL member libraries. She documented the growing acceptance of e-journals by scholars in research institutions. ${ }^{14}$ Sally A. Rogers reported on a usage survey of Ohio State University faculty with data collected in 1998, 1999, and 2000, enabling a detailed reporting of the change in faculty perception and usage over time. ${ }^{15} \mathrm{All}$ of these studies describe faculty increasingly comfortable with e-journals and less attached to their print counterparts.

An area that remains largely unstudied is the impact on the daily work of faculty, specifically on teaching and research methods. This study examines the quality, rather than the quantity, of work and was intended to open up discussions with faculty on e-journals, other closely related issues pertinent to the library, and any related topics the faculty chose to explore.

\section{Methodology}

Sociologist Everett M. Rogers's Diffusion of Innovations offers a conceptual framework for understanding the adoption of technological innovations. ${ }^{16}$ Karla L. Hahn and Natalie A. Schoch applied Rogers's diffusion theory to an analysis of electronic publishing by characterizing the set of activities that comprises electronic publishing as a cluster of related and interdependent innovations. Hahn and Schoch identified changing publishing roles; distribution and retrieval innovations; innovations in document structure; new approaches to validation of research; new economic models, including licensing; and storage innovations as components of the electronic publishing innovation cluster. ${ }^{17}$ Their approach recognized the complexity of the adoption decision process that, they assert, would generally involve simultaneous adoption of several elements 
and offers the potential to interpret the type of qualitative data the investigators expected to collect in the current project.

Rogers described the roles of "early adopters" and "innovators" as leaders in the acceptance of innovation, and the present study assumes the existence of such individuals among faculty members in the basic and health sciences at the University of Illinois at Chicago (UIC). The current study focused on the disciplines listed in figure 1 , which were among the first to see a critical mass of e-journals.

Faculty members who appeared to be users of electronic resources were identified, and participants were asked to suggest colleagues who also might consent to be interviewed. The identified faculty were contacted by phone or e-mail, and appointments were confirmed with a follow-up letter and a discussion guide to give participants a better understanding of the information being sought (figure 2). Participating faculty were visited in their offices by two investigators. One investigator conducted the interview; the other took notes on a response sheet that listed the questions asked. No personal identification of the study participant was recorded on the response sheet, and no personal information was retained that would allow a respondent's anonymity to be compromised. Because this research used human subjects, the investigators submitted documentation to the university's Institutional Review Board (IRB), which monitors all human subject research on campus. The IRB approved the protocol.

More than thirty faculty members were initially identified, representing a broad cross section of basic, applied, and health sciences disciplines. In the interviews, participants were asked to identify other colleagues who were early adopters of electronic resources to expand the study population. Some initially identified did not actually hold faculty positions, some had left the university, and others were too busy to participate. In the end, about half of the original contact list agreed to participate in the study and further contacts brought the final number of participants to nineteen.

\begin{tabular}{|l|}
\multicolumn{1}{c|}{ FIGURE 1} \\
Specialties of Faculty Interviewed \\
\hline - Chemical engineering \\
- Health information sciences \\
- High-energy physics \\
- Medical education \\
- Medicine \\
- Medicinal chemistry \\
- Minerobiology \\
- Molecular biology \\
- Molecular genetics \\
- Neurobiology \\
- Organic chemistry \\
- Paleontology \\
- Pediatrics \\
- Pharmaceutical biotechnology \\
- Pharmacy practice \\
- Surgical nursing \\
\hline
\end{tabular}

\section{Scope and Hypotheses}

The investigators used the discussion guide to give structure and consistency to the interviews. Questions were designed to elicit responses from participants on those features of e-journals and other electronic resources that the investigators speculated would influence acceptance of the resources. The questions were intentionally open ended to allow participants to provide details of their use of resources that would go beyond the structured responses of a survey instrument. Both previous research and the investigators' own experiences suggest that adoption of electronic resources by research scientists is a complex process influenced by their participation in the system of scientific communication as both producers and users of information.

The following characteristics of e-journals were hypothesized to be key determinants in the adoption process:

1. Content characteristics

- Critical mass of issues and volumes in a given title

- Critical mass of titles in a subjectdelineated collection provided by an aggregator 


\section{FIGURE 2 \\ Faculty Use of Digital Collections Discussion Guide}

As you are aware, the UIC library is building a collection of e-journals or "ejournals." The following questions relate to your use of these. For the purposes of this discussion, we are defining an "e-journal" as a scholarly journal that is available on the Internet and may or may not have a print version.

1. How did you first learn of e-journals?

2. How often do you use e-journals? Daily $\square$ Weekly $\square$ Monthly

3. Which ones?

4. Do you have any bookmarked in your Web browser?

5. How do you get to them?

$\square$ Personal subscription $\square$ Library Web page list of e-journals

$\square$ Hot links in other articles or databases $\square$ UICCAT

Through a publisher or aggregator's collection on the library Web pages

$\square$ Other

6. What do you use e-journals for?

$\square$ Scan latest issue articles $\square$ Scan tables of contents

$\square$ Search for subject or author $\square$ Read preprints on the journal Web site

$\square$ Set up SDI / personal alert service $\square$ Search for cited article $\square$ Other

7. Do you search publishers' (aggregators') collections by subject or author?

8. Do you read full articles on your computer screen?

9. Do you print articles of interest?

10. What features do you expect to find in an e-journal (more data than in print, graphics, video, audio links, etc.)?

11. What extra features do you particularly appreciate when they are present?

12. What would be the most innovative feature you can imagine?

13. What do you dislike/find frustrating about current e-journals?

The next questions pertain to other electronic resources available on the Internet and to your use of the Internet to communicate with colleagues.

14. What other Web-based resources do you use?

$\square$ Databases $\square$ Data banks (Human Genome Project, chemical libraries, etc.)
$\square$ Preprint archives $\square$ Association/organization Web pages $\square$ Other

15. How can the library help you with this type of material?

$\square$ Instruction in use $\square$ Notification of new resources $\square$ Easier access $\square$ Other

16. Has electronic access to information changed the way you do research, publish, or teach?

17. Are you actively involved in electronic publishing in any way (serve on board of an e-journal, contribute or edit one, etc.)?

18. Are you involved in any collaborative research project where data are shared on the Internet? Please describe.

19. Is there anything else on a related topic you would like to discuss? 
- Full equivalence to print issues, including all articles and other content, whether research or other information

- Timeliness of appearance, before or simultaneous with appearance in print

2. Functionality characteristics

- Searching capabilities that support browsing, locating known articles, and subject/author retrieval

- Ease of navigation with minimal need to view screens not directly related to a user's goal in using the resource

- Links to other articles, abstracts, email for authors, and so on

- High-quality printing capability

- Seamless movement among related resources

\section{Shared Behaviors and Values}

Although individual respondents were treated as discrete case studies, each respondent's specialty was recorded to correlate discipline-specific patterns and trends. After interviewing all the participants, their responses were analyzed to identify both patterns of informationseeking behavior and emerging trends in the use of digital collections.

The participants had been chosen based on their known use of e-journals. Some participants would be described by Rogers as "innovators," those who are among the very first to adopt and use a new technology long before its use is widespread or proven, ahead of early adopters. Some lag slightly behind "early adopters" and would be classified by Rogers as "early majority," those who adopt a technology earlier than most but wait for others to demonstrate its effectiveness. Several participants could fit more than one definition, innovative in one area, such as their use of multimedia, and yet completely oblivious to other aspects of digital collections, such as the emergence of exclusively electronic refereed journals. Using Hahn and Schoch's characterization of electronic publishing as an innovation cluster accommodates the variety of uses of digital collections that the study participants reported. All of the subjects have adopted some of the innovations that comprise the electronic publishing cluster. Given the selection criteria, as expected, the chosen participants were ahead of their peers in terms of e-journal adoption and most fall under Rogers's umbrella of "Opinion Leaders," those whose experience tends to influence the community in the adoption of the innovation. ${ }^{18}$

Across disciplines, all participants have fully assimilated use of bibliographic databases into their information-seeking behavior. They all use e-mail to communicate with colleagues and search the Web to locate information. Further, they all read e-journals at least weekly, and many use them on a daily basis. The only participant who did not testify to the profound change brought by electronic access on daily work was one young enough never to have relied on print access alone.

\section{Despite the enhanced navigation, however, few participants were willing to read full articles on their computer screens.}

Study participants in all specialties shared certain expectations of e-journal content and functionality. Everyone wanted digital content fully equivalent to print issues, including news articles, position notices, and so on, as hypothesized, but other anticipated characteristics, such as critical mass of a title, critical mass of titles in a subject-delineated collection, or timeliness of appearance, were not articulated as primary concerns but, rather, implicitly expected. This is consistent with other research recently published by Hurd, Blecic, and Robinson. ${ }^{19}$ Virtually all the respondents were either unaware or dismissive of journals that existed as electronic-only publications; those who professed knowledge of such "e-only" titles expressed reservations about their quality. The value of peer-reviewed journal content as an indicator of quality is shared by all participants. This is consistent with findings reported by Hahn, who interviewed faculty in ecology and found them supportive of the quality filtering provided 
by peer review. ${ }^{20}$ When participants were asked to name specific titles they read frequently, everyone identified high-impact, rigorously peer-reviewed journals in their fields that also have seen heavy use in print. To date, faculty in a research university environment have not accepted newer forms of publication with different ways of vetting or validating content.

Study participants were in agreement on several key functionalities of e-journals, and all study hypotheses were validated to some degree. Many participants use e-journals to obtain articles for which they have a citation. They also search for articles by author or subject within a specific title or collection of titles, just as with familiar print journals. In addition, many participants follow hyperlinks embedded in articles and databases, and expressed appreciation for the ability to navigate across full-text articles in various journals. They saw this feature as one of the ejournal's most desirable attributes. Despite the enhanced navigation, however, few participants were willing to read full articles on their computer screens. Most scanned the full text for relevance but printed articles of interest, uniformly preferring the PDF versions for that purpose. E-journal providers that did not offer PDF versions of articles were criticized. A small number of participants reported bookmarking articles for later reference; most continue to build reprint collections and now rely on e-journals and in-office printers rather than library photocopiers for their copies. Several mentioned their use of citation manager software to organize their collections and spoke about the desirability of database formats compatible with software such as EndNote.

The Web environment offers numerous pathways to e-journal content, and participants used any or all of them. Most frequently mentioned was the library's list of e-journals as the preferred route to content, but some users followed links in the catalog and others in database services such as PubMed or SciFinder Scholar. Still others reported bookmarking publishers' Web sites or using association pages to link to favorite journals. One physicist had developed his own personal Web site with all his most-used URLs.

The study found that enthusiastic acceptance of e-journals has changed the participants' habits. Fewer visits to the library were necessary, although some scientists still enjoyed browsing through print journals. Most claimed they were reading more than in the print era and across a broader array of titles. Moreover, many participants seized the opportunity to suggest titles they felt should be added to the library's digital collection. Many were well informed about archiving and expressed concern about the long-term availability of content that existed only digitally.

Most participants expressed a strong interest in timely notification of new library resources. They mentioned learning of new electronic resources through numerous channels, including the scientific literature itself, the popular media, and an existing library listserv designed for such announcements. Although some participants have-and continue to useautomatic alerting services, many have discontinued their use, claiming information overload. Nearly all are emphatically uninterested in formalized classroom instruction on the use of electronic resources because of time constraints and the preference to learn about such things through trial and error. They will call or e-mail library reference personnel with any access or searching problems as they arise.

\section{Discipline-dependent Variations}

Many aspects of faculty attitudes toward, and use of, electronic resources were common across all disciplines, but there were some differences as well. Appreciation for the multimedia capabilities of e-journals appears to vary among specialties and may be related to the importance of a specific format in conveying information in a field. For example, a microbiologist demonstrated an animated image of "an enzyme as it is catalyzing a chemical reaction." This animation "demonstrates to [his] colleagues visually what cannot be 
communicated in print or in a series of images nearly as effectively." In chemistry, the three-dimensional representation of molecules can be enhanced by both static and dynamic image files associated with articles, although one chemist regarded them as "glitz" and preferred the option to activate such features, depending on his level of interest. Several participants noted that the now-common static representations of complex biological molecules use color to carry information about substructure, which makes color printers essential for those wishing to print an image of a molecule.

Participants were asked about their use of "preprints," which have long been part of the culture of specialties in physics. One participant in a medical specialty professed no knowledge of preprints. A chemist knew of their existence but was dismissive and commented that he ignored such things on a curriculum vitae or grant application. They "don't count," he commented. Still other participants reported that they sometimes looked at prepublication articles on journal Web sites, but because these articles have been reviewed and, in fact, are "in press, they are not truly unvetted "preprints." On the issue of preprints, the variations across disciplines were striking, which suggests that the high-energy physics communication system that relies on preprint databases will not necessarily serve as a model for other fields.

Use of databases to identify articles in the journal literature varies across disciplines. In the health sciences specialties, PubMed is used by most participants to the exclusion of other resources that might be complementary. Some participants from the medical faculty were unaware of the availability of the Web of Science (the citation indexes), despite its potential relevance to research in their field. Newer tools such as MDConsult and the Cochrane database (a growing collection of metaanalyses) also are being adopted by many faculty members in medicine. In specialties that used chemical information, SciFinder Scholar and the Beilstein/
Gmelin databases were the preferred tools for literature searching. Some participants reported using these resources on a daily basis. In other basic sciences fields, participants use the Web of Science rather than the discipline-specific resources such as Geo-Ref. Still others apparently do not rely on any secondary services but, instead, search individual journals they perceive as most likely to contain research of interest.

Several health sciences participants now operate in environments being transformed by the principles of evidencebased medicine (EBM), a cross-disciplinary effort to train medical professionals to make clinical decisions based on the most recent reliable evidence, with a systematic elimination of bias as its central tenet. Although EBM predates e-journals, its practical implementation has certainly coincided with the general accessibility of e-journals. EBM has pervaded the curriculum at medical schools for a number of years, and its practices have provided structure for most of the medical school's library instruction sessions, facilitated by the relative ease of electronic access to research articles.

\section{Changing Research Habits}

Research practices have changed considerably with the onset of electronic resources. One microbiologist claimed he would "be dead without" electronic access. Literature searching is now timelier, with a wide variety of databases and e-journals available through the desktop, requiring fewer trips to the library. Electronic access does more than make life more convenient for faculty, it allows for a greater amount of follow-up on relevant cited articles and thus more comprehensive literature reviews. A professor of medicine claimed he does not "need to retain knowledge as long as access is maintained," a change in the basic approach to the body of knowledge and the fundamental role of the professor because "the aggregation of knowledge is now paramount." Another professor of medicine mentioned aggregation when discussing the explosion of the meta-analysis, a process that was so cumbersome and 
time-consuming in the past that it was rarely practical to undertake.

Virtually every participant in the study shares data electronically with colleagues at other institutions. Still other participants in specialties where research generates large data sets noted the value added when articles included links to raw data, whether in genome databases, on author or publisher servers, or elsewhere. A molecular biologist described using a university Web site where genetic data were freely available to any interested scientists and where software was provided that could be used to manipulate the data. In chemistry and physics, supplementary data once were distributed in microform by journal publishers; now major publishers provide Web sites that can be linked in article text, making access to such detailed data only a click away.

Because electronic access also has sped up and streamlined the process of article submission, some of the questions probed participants' views as authors. Faculty appeared to be actively involved in publishing roles, for example, serving on editorial boards of journals. This was frequently the case when the individual's specialty was published in small association journals. One participant was a Web master for an association Web site, and the participant pool included several editorial board members and association officers. These individuals were articulate about many of the same issues that concern librarians, such as archiving. Three participants were involved in ARL's Scholarly Publishing and Academic Resources Coalition (SPARC) initiatives. A chemist, who served on the editorial board of the SPARC publication Organic Letters, observed that he considered that title to have achieved the level of quality of its high-impact print competitor Tetrahedron Letters. At the same time, however, he said he would be most unhappy if the university canceled the library subscription to Tetrahedron Letters.

\section{Changing Teaching Habits}

Conversations with faculty suggested that electronic access has had somewhat less impact on teaching than on research. Many participants are assigning readings from e-journals to their graduate-level students. They also are increasingly incorporating issues and techniques related to electronic access into their lectures, assignments, and interactions with advisees and residents.

The impact is greatest for those departments that have online degree programs, and e-journal access is particularly vital for this constituency. For example, a full 50 percent of the courses offered by the School of Biomedical and Health Information Sciences are available exclusively online, where one professor claims electronic ac-

Although some of the participants
interviewed stated that they prefer to
scan the latest issue in print even
when an electronic version is
available, anecdotal evidence does
not indicate heavy use of print titles
also held in electronic format.

cess has "completely transformed the education process." Indeed, several degrees can be earned without ever coming to campus. The library now can provide such students a broad representation of the literature through licensed e-journals, albeit a fraction of the library's full journal collection. "Coursepacks," bound copies of various articles arranged by the instructor and sold at the campus bookstore, were a mainstay of many campus courses, and delivery of such materials to off-campus students was a problem that can now be avoided. The library has implemented electronic reserves to facilitate such efforts and fields many more inquiries about copyright concerns in the new mode of delivery. All of these resources are available to students twenty-four hours a day.

Many participants felt that students' searching and critical evaluation skills are more vital than ever and devote extra class time to covering these topics. Even participants uninterested in library instruction for themselves arrange such sessions for their students and find that students are more appreciative of the extra classes. However, some participants are 
leery of what this evolution may mean to their students. One professor from the biological sciences worried that students do not get a solid introduction to the breadth of the journal literature of the field through electronic access and felt that sometimes browsing the stacks gives a proper perspective. A medical professor was gratified to be able to send electronic copies of important studies to residents but feared that residents "will become dependent on [him] for new articles, and less self-sufficient."

\section{Challenges for the Library}

Participants appear to be satisfying their current information needs by browsing the digital equivalent of favorite titles. In the Science Library, this was particularly dramatic when Elsevier ScienceDirect titles in chemistry were made available. Although some of the participants interviewed stated that they prefer to scan the latest issue in print even when an electronic version is available, anecdotal evidence does not indicate heavy use of print titles also held in electronic format. In addition, entrance/ exit statistics at all library sites have demonstrated a downward trend for several years: fewer patrons are choosing to visit the library. However, measures of use of electronic resources of all types continue to increase. When data for use of print and digital formats of specific journals or databases are available, they frequently document levels of use of electronic information higher than estimated print use. This is consistent with a trend of searching the easily accessible and only concerning themselves with a comprehensive search of the full literature available in print when more is at stake, such as a complex clinical decision or a grant application. For some participants, the library is being completely bypassed: participants are going directly to association pages for portal functions and to vendor Web sites for personal subscription access.

Users of databases and e-journals choose to do so because they see advantages related to time saving, ease of use, powerful searching capabilities, and more.
As producers of electronic resources improve their products, users adopt new features and quickly adjust their expectations. Participants are interested in more e-journal titles and more extensive digitization, especially retrospectively.

From interviews with participants, the investigators identified a number of challenges, including:

- meeting enhanced expectations for electronic resources, given licensing and budgetary issues;

- anticipating new directions in publication, synthesis, and integration of primary research;

- affirming the library's role in the provision of resources (i.e., branding);

- communicating with the library's constituency;

- measuring collection use.

The growing reliance on digital information brings many new responsibilities for library staff, such as client software support, proxy servers, firewalls, and licensing issues. Faculty come to the library less often, so innovative outreach methods are necessary to inform them of library electronic resources and the techniques to search them. Innovation and sophistication of faculty in one area does not mean comprehensive understanding in all areas, and the library must assess strengths and weaknesses effectively and respond appropriately. Time is the faculty researcher's most valuable resource, so the outreach effort should be made as convenient, accessible, and flexible as possible.

Participants understand that the majority of electronic resources were available to them through library subscriptions. Those participants whose favorite titles were unavailable electronically, frequently because of licensing barriers for the library, took the opportunity to urge the library to provide access and were not always sympathetic to its concerns about restrictive licenses. On the other hand, some participants appeared not to be fully aware of the library's role in providing access. This may have been especially common among those who went directly to publishers' sites to connect to journals, not realizing that 
the library's subscription (recognized through IP address rather than password access) made it possible for them to use full text. Libraries are challenged to provide users with what some call "branding" to make it clear that access is provided by the library and typically involves expensive contracts and complicated licenses.

The very first e-journals were text only and often distributed as e-mail. With the growth of the World Wide Web, truly innovative formats developed with markedup text supporting links to other text and an array of multimedia enhancements. Especially appreciated by researchers are the links possible in the Web environment, whether from a database record to a fulltext article or from one article to another. Linking services such as PubMed's Linkout, Chemical Abstract Services's ChemPort, SFX, and CrossRef are approaches that facilitate the full integration and seamless linking that users desire. During the present time of transition when some, but not all, possible links are present, library staff are challenged to explain the complexities of access. For example, the recent introduction of SciFinder Scholar with direct links to full-text articles through its ChemPort connection stimulated inquiries about whether the library held electronic subscriptions to titles that are not linked in SciFinder Scholar.

Librarians also must seek new ways to communicate with patrons who visit the library infrequently, preferring, instead, to use the electronic resources it provides from home or office or elsewhere across the globe. Although some faculty members may attend an instruction session, others feel too busy or just not inclined. Web-based help, electronic reference, chat rooms, and other ways of interacting with remote users are increasingly the preferred avenues of assistance.

\section{Conclusion}

Users are adopting different behaviors as they use resources that are increasingly electronic, and the patterns of use of secondary services that prevailed in the print world of indexes and abstracts may not transfer to a digital environment. The participants in this study frequently mentioned using PubMed, the Web of Science, SciFinder Scholar, and the Beilstein/ Gmelin databases, but few seemed to rely on any of the smaller discipline-specific databases that they might once have searched in print or through mediated searches executed by librarians. Whether the smaller databases will survive is subject to speculation. Will only the comprehensive services that offer powerful retrieval across a broad set of disciplines or provide specialized searching such as using chemical structures be perceived as useful? At the same time, new tools with no print counterparts, such as MDConsult, are organizing and synthesizing literature for specific audiences.

The wide-ranging discussions with participants produced unanticipated opportunities in faculty relations with librarians. As Sandra J. Weingart and Janet A. Anderson reported in their 2000 study, quite often the questions that were asked had the effect of informing participants of new resources and trends. ${ }^{21}$ In nearly every interview, the investigators were able to clear up a misconception or inform participants about library resources and services. Some participants appeared gratified to voice personal concerns to someone from the library. This benefit is ironic in light of the assertion of many participants that they would not bother with library instruction. The interviews allowed the investigators to deliver some instruction to the participants somewhat surreptitiously.

The present is a time of rapid change for readers, authors, libraries, and publishers with evolving roles and new players. It is clear that the observations in this study are snapshots of an early stage in a process of transition and evolution. Additional research, such as Susan E. Searing and Leigh S. Estabrook's focus group study on chemists' adoption of emerging Webbased scholarly publishing initiatives, is necessary to supplement the snapshot provided here and to track emerging developments that postdate the innovations known at the time of this study. ${ }^{22}$ Faculty's 
opinions and concerns in these matters shift and grow every day. Indeed, once, a mild epiphany transpired right before the authors' eyes: When discussing the quality of exclusively online journals, one professor first responded dismissively, as if such publications had no chance of credibility in his field. Then, as he pondered the possibility of a journal with the same policies of peer review and a clear policy of archiving and long-term accessibility, he started to doubt his initial reaction.

\section{Notes}

1. Carol Tenopir and Donald W. King, Towards E-journals: Realities for Scientists, Librarians, and Publishers (Washington, D.C.: Special Libraries Association, 2000).

2. Carol Franck and Holly Chambers, "How Full Is the Full in Full-Text?" Poster session presented at the ALA annual conference in Washington, D.C., June 1998. Available online from http://www2.potsdam.edu/LIBR/franckcr/ALA.html.

3. Shelley Shaffer, Susan S. Berteaux, Brandon Oswald, and Peter Breuggeman, "Going Electronic? Receipt of Print Journal Issues and their Electronic Availability," in Proceedings of the $25^{\text {th }}$ International Association of Aquatic and Marine Science Libraries and Information Centers Annual Conference (Woods Hole, Mass.: Oct. 1999).

4. Narda Tafuri, "What a Scientist Really Wants from E-journals (Report from the 1998 Charleston Conference)," Library Collections, Acquisitions \& Technical Services 23, no. 2 (summer 1999): $216-17$.

5. Sarah Pedersen and Rosemary Stockdale, "What Do the Readers Think? A Look at How Scientific Journal Users See the Electronic Environment," Journal of Scholarly Publishing 31 (Oct. 1999): 42-52.

6. Christie T Degener, "The Impact of E-journals in the Medical Library Setting," Serials Review 25, no. 3 (1999): 48-49.

7. Alan Dawson, "Inferring User Behaviour from Journal Access Figures," Serials Librarian 35, no. 3 (1999): 31-41.

8. Linda S. Mercer, "Measuring the Use and Value of E-journals and Books," ISTL (Issues in Science and Technology Librarianship) 29 (winter 2000). Available online from http:// www.library.ucsb.edu/istl/00-winter/article1.html.

9. Deborah D. Blecic, Joan B. Fiscella, and Stephen Wiberley, "The measurement of Use of Web-based Information Resources: An Early Look at Vendor-supplied Data," College E Research Libraries 62, no. 5 (Sept. 2001): 434-53.

10. David H. Morse and William A. Clintworth, "Comparing Patterns of Print and Electronic Journal Use in an Academic Health Science Library," ISTL (Issues in Science and Technology Librarianship) 28 (fall 2000). Available online from http:/ / www.library.ucsb.edu/istl/00-fall/refereed.html.

11. Sandra L. DeGroote and Josephine Dorsch, "Online Journals: Impact on Print Journal Usage," Bulletin of the Medical Library Association 89, no. 4 (Oct. 2001): 372-78.

12. Suely Gomes and Jack Meadows, "Perceptions of Electronic Journals in British Universities," Journal of Scholarly Publishing 29 (Apr. 1998): 174-81.

13. Susan E. Hahn, Cheri Speier, Jonathan Palmer, and Daniel Wren, "Advantages and Disadvantages of Electronic Journals: Business School Faculty Views," Journal of Business and Finance Librarianship 5, no. 1 (1999): 19-31.

14. Deborah Lenares, "Faculty Use of E-journals at Research Institutions," in Conference Proceedings, Association of College and Research Libraries $9^{\text {th }}$ National Conference, Detroit, Mich. (Apr. 1999), 329-34.

15. Sally A. Rogers, "Electronic Journal Usage at Ohio State University," College E Research Libraries 62 (Jan. 2001): 25-34.

16. Everett M. Rogers, Diffusion of Innovations (New York City: Free Press, 1995).

17. Karla L. Hahn and Natalie A. Schoch, "Applying Diffusion Theory to Electronic Publishing: A Conceptual Framework for Examining Issues and Outcomes," in Proceedings of the $60^{\text {th }}$ ASIS Annual Meeting, Washington, D.C. 34 (Nov. 1997), 5-13.

18. Rogers, Diffusion of Innovations.

19. Julie M. Hurd, Deborah D. Blecic, and Ann Robinson, "Performance Measures for Electronic Journals: A User-centered Approach," Science E Technology Libraries 20, no. 2-3 (2001): 57-71.

20. Karla Hahn, Electronic Ecology: A Case Study of Electronic Journals in Context (Washington, D.C.: Association of Research Libraries, 2001), 79.

21. Sandra J. Weingart and Janet A. Anderson, "When Questions Are Answers: Using a Survey to Achieve Faculty Awareness of the Library's Electronic Resources," College and Research Libraries 61, no. 2 (Mar. 2000): 127-34.

22. Susan E. Searing and Leigh S. Estabrook, "The Future of Scientific Publishing on the Web: Insights from Focus Groups of Chemists," Portal: Libraries and the Academy 1, no. 1 (2001). Available online from http://muse.jhu.edu/journals/portal_libraries_and_the_academy/v001/1.1searing.html. 